\title{
A cada ausência tua eu vou te amar
}

\author{
Denise L Madureira $^{(1)}$
}

\section{Resumo}

O trabalho trata a descrição do caso clínico de uma criança, fruto de gestação gemelar e com histórico de prematuridade e baixo peso extremos, que ao longo da sua evolução desenvolveu um quadro de enterocolite necrotizante. Todos esses fatores, aliados à morte de seu irmão gêmeo, culminaram em um quadro de distúrbio alimentar, principal causa da demanda fonoaudiológica. Ao longo dos atendimentos realizados à beira do leito hospitalar, evidenciou-se que a causa da recusa alimentar ultrapassava os limites de natureza puramente orgânica.

Palavras chave: distúrbio alimentar; vínculo; enlutamento

Madureira, Denise L. "A cada ausência tua eu vou te amar", in Anais do 20. Congresso Internacional Sabará de Especialidades Pediátricas 
O trabalho expõe o relato do atendimento fonoaudiológico realizado com uma criança com histórico de internação prolongada devido a nascimento prematuro e baixo peso extremos. A criança foi atendida no leito da Unidade de Terapia Intensiva de um hospital da cidade de São Paulo por um período de quatro meses, com o principal objetivo de introduzir a alimentação. Devido a incontáveis intercorrências que ocorreram ao longo de sua permanência no hospital, a criança desenvolveu um quadro grave de distúrbio alimentar. Para a análise do presente estudo, buscou-se a teoria psicanalítica como embasamento da compreensão da constituição do sujeito.

O trabalho fonoaudiológico hospitalar com enfoque na alimentação trabalha diretamente com as funções orais da criança. No entanto, a medida de eficácia da intervenção fonoaudiológica não pode ser avaliada somente por meio do estímulo mecânico para aumentar o desempenho das funções orais. Torna-se fundamental que ao realizá-lo, o profissional tenha a consciência da importância do lugar da pulsão oral para a constituição psíquica e o lugar privilegiado da boca como zona erógena.

(SALES, L.)

Um outro ponto que merece ser lembrado é que na vida de uma criança com um período de internação prolongado e com uso de via alternativa de alimentação, ocorre o impedimento da vivência da boca como fonte de contato com o outro e como fonte de prazer capaz de saciar a sua fome.

$\mathrm{O}$ atendimento fonoaudiológico desta criança expôs de forma clara que existe um limite de abrangência terapêutica, que ultrapassa o arsenal dos aparatos técnicos e da disponibilidade do terapeuta. Neste caso, os limites foram revelados pela própria criança, cuja recusa em se alimentar não encontrava justificativa dentro do seu exame físico e nem dentro de sua capacidade neuro- anatomofuncional, cujas possibilidades eram indiscutíveis. O desfecho foi então ditado pela sua morte inesperada, causada por uma parada cardíaca irreversível.

O estudo do presente caso ilustra a necessidade de ampliar a visão do terapeuta quando se depara com pacientes cuja demanda pode ultrapassar o contrato a priori estabelecido.

“...ao fechar a boca enquanto puro orifício real de alimentação, o bebê tenta convocar o outro em sua dimensão libidinal(..) Inevitavelmente isto angustia demais o Outro materno, pois o desconserta no intuito de "cumprir suas obrigações..." ( SALES, L).

\section{English Title}

The paper treats the case description of a child, the result of twin pregnancy with a history of extreme prematurity and low weight, which throughout its evolution has 
developed necrotizing enterocolitis. All these factors combined with the death of his twin brother, culminated in complications and development of food disorder, major cause of this demand. During the care provided at the bedside, it was revealed that the cause of food refusal was multifactorial.

Keywords: Eating disorder, bond, grieving

\section{Referencias}

DOLTO, F. Pediatria e Psicanálise. Rio de Janeiro,Ed. Guanabara Koogan,1988.pag. 29-32

ELIACHEFF, C. Corpos que gritam. São Paulo ,Editora Ática, 1995

SALES, L(org). Pra que essa boca tão grande. São Paulo, Ed. Ágalma, 2005. pag. 145-47 WAIBLINGER, A. A grande mãe e a criança divina. Ed. Cultrix. SP, 1986.

(1) Fonoaudióloga. Mestre em Fonoaudiologia. Coordenadora do setor de Fonoaudiologia do Hospital Infantil Sabará. 